The illustrations are admirably reproduced. All concerned in the production of this new venture are to be congratulated on the excellence of the results.

\title{
CORRESPONDENCE
}

\section{INTRA-OCULAR FOREIGN BODIES}

To the Editors of THE BRITISH JOURNAL OF OPHTHALMOLOGY.

DEAR SIRS, - In their interesting article on the removal of intraocular foreign bodies by the trans-scleral route, Messrs. Kraus and Briggs do rather less than justice to those who practised, taught and published this technique before the war; but perhaps they are far removed from reference libraries, and so may be forgiven. Now that the method has become established in this country it is as well to recall it's early. struggles.

In this country the Haab magnet has always been more popular than the Mellinger, and the Haab is not ideal for the trans-scleral removal of foreign bodies. Perhaps for this reason the method has only been used as a last resort when all else had failed, and as the sclera was not sutured it is not surprising that the published results were very bad. I think I am right in saying that Cridland, in his Doyne Memorial Lecture on this subject, was inclined to the view that the results of extraction by the posterior route were so bad that there was little difference in the prognosis whether the foreign body was left in or removed.

In America, where many have used the posterior route as the method of preference, and not as a last resort, very different results have been obtained. The pioneer and arch exponent was William Sweet of Philadelphia, who had, by 1914, published the results of 1,000 cases treated by this method by his colleagues and himself. The results then compared favourably with those by any other method in any other country.

It is interesting to recall the somewhat lively meeting at the Ophthalmological Congress early in 1942, when I produced results in patients treated by the posterior route with suture of the sclera. They were mostly pre-war cases which had been followed up. The older members of the congress were mostly dead against the method, and I remember some of them being quite angry. It soon became clear that the modern operation differed so widely from the older operation practised by them that no exact comparison was possible. Now that the war has brought a glut of these cases, and has allowed 
surgeons of experience to form a considered opinion of the best method of treatment, it seems clear that the planned transcleral method will have a considerable following in this country in future.

104, Harley Street, W:1

$$
\begin{aligned}
& \text { I am, Yours faithfully, } \\
& \text { SEYMOUR PHILPS. }
\end{aligned}
$$

November 18, 1945.

\section{EXPERTMENTAL CORNEAL LESIONS}

To the Editors of THE BRITISH JOURNAL OF OPHTHALMOLOGY. DEAR SIRS, - In their letter in your December issue, Dr. Robson and his associates reiterate their claim that they have evolved a satisfactory experimental lesion of the cornea for testing the efficacy of chemotherapeutic agents. My colleagues and myself have found these lesions too inconstant in course to serve such a purpose. Moreover, these lesions tend to heal spontaneously. Our criticism, far from being " uninformed," is based on a considerable amount of experimental and clinical work reported in your columns and elsewhere. We are satisfied that in repeating the work reported by Dr. Robson and his colleagues we have taken all the care that could reasonably be expected, even to such a detail as to use the specially bevelled needles they employed:

Incidentally, have hectic adjectives any place in a scientific discussion? They are not known to influence the rabbit's cornea.

Yours faithfully,

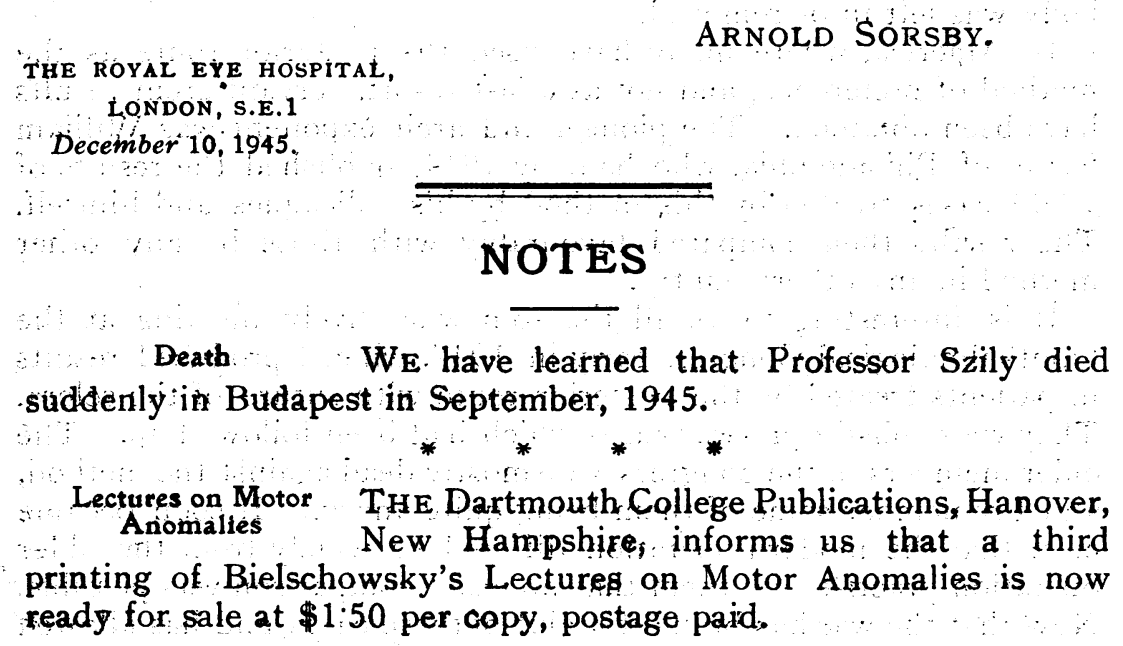

